\section{Pacific Northwest}

National Laboratory

Operated by Battelle for the

U.S. Department of Energy

\title{
Improving a Gripper End Effector
}

\author{
OD Mullen \\ CM Smith \\ KL Gervais
}

January 2001

Prepared for the U.S. Department of Energy under Contract DE-AC06-76RL01830

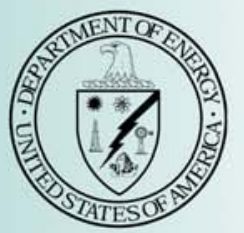




\title{
DISCLAIMER
}

This report was prepared as an account of work sponsored by an agency of the United States Government. Neither the United States Government nor any agency thereof, nor Battelle Memorial Institute, nor any of their employees, makes any warranty, express or implied, or assumes any legal liability or responsibility for the accuracy, completeness, or usefulness of any information, apparatus, product, or process disclosed, or represents that its use would not infringe privately owned rights. Reference herein to any specific commercial product, process, or service by trade name, trademark, manufacturer, or otherwise does not necessarily constitute or imply its endorsement, recommendation, or favoring by the United States Government or any agency thereof, or Battelle Memorial Institute. The views and opinions of authors expressed herein do not necessarily state or reflect those of the United States Government or any agency thereof.

\author{
PACIFIC NORTHWEST NATIONAL LABORATORY \\ operated by \\ BATTELLE \\ for the \\ UNITED STATES DEPARTMENT OF ENERGY \\ under Contract DE-AC05-76RL01830
}

Printed in the United States of America
Available to DOE and DOE contractors from the Office of Scientific and Technical Information,
P.O. Box 62, Oak Ridge, TN 37831-0062;
ph: (865) 576-8401
fax: $(865)$ 576-5728
email: reports@adonis.osti.gov

\begin{abstract}
Available to the public from the National Technical Information Service, U.S. Department of Commerce, 5285 Port Royal Rd., Springfield, VA 22161 ph: (800) 553-6847 fax: $(703) 605-6900$ email: orders@ntis.fedworld.gov online ordering: http://www.ntis.gov/ordering.htm
\end{abstract}

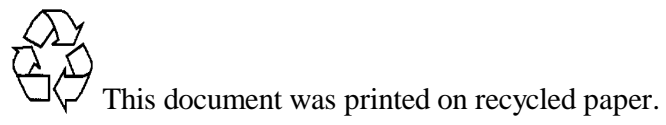




\title{
IMPROVING A GRIPPER END EFFECTOR
}

\author{
O. Dennis Mullen \\ Sr. Development Engineer \\ Battelle \\ MS K5-22 2400 Stevens Dr. \\ Richland WA 99352 \\ Ph: 509-375-2395 fax: 509-375-2379 \\ dennis.mullen@pnl.gov \\ Christopher M. Smith \\ Principal Engineer \\ SIGN - Surgical Implant Generation Network \\ 2950 George Washington Way \\ Richland, WA 99352 \\ Ph: (509) 371-1107, FAX 371-1316 \\ chris@sign-post.org \\ Kevin L. Gervais \\ Science \& Engineering Associate \\ Battelle \\ MS K5-22 2400 Stevens Dr. \\ Richland WA 99352 \\ Ph: 509-375-6536 fax: 509-375-2379 \\ Kevin.gervais@pnl.gov
}

January 8, 2001

\begin{abstract}
This paper discusses the improvements made to an existing four-bar linkage gripping end effector to adapt it for use in a current project. The actuating linkage was modified to yield higher jaw force overall and particularly in the critical range of jaw displacement.
\end{abstract}




\section{PROBLEM}

Battelle was tasked with providing a gripper end effector (GEE) for a new robotic arm (Grey Pilgrim's EMMA) for retrieval of nuclear materials processing wastes from two large storage silos. The GEE had two primary functions. It was required to grasp debris such as pipe, wire, small containers, tools, and the like and place them into a cutting device or a retrieval basket. It was also required to grasp a waterjet retrieval end effector (WREE), a jet pump and a large umbilical with special grip fixtures along its length.

The debris retrieval function required a strong grip over the full range of jaw opening $(\sim 15 \mathrm{~cm})$. Some textured mating areas for general-purpose grasping are machined on the jaws. The end effector grasping function required high grip force only at a partially closed jaw position, where the jaws engage the grip fixture.

We chose to base the design on a gripper originally designed for the Light Duty Utility Arm by Southwest Research Institute. Prior testing and experience with that gripper had identified some needed controls enhancements and functional improvements, The kinematic study described here showed that significant increase in grip force could be achieved with a few minor revisions to the linkage geometry. A cursory study of the LDUA gripper kinematics showed that it would produce the highest forces at the fully open jaw position, and that the force would vary by a factor of about 3.7 over the range of jaw motion. There is some logic to such a distribution of force, in that larger objects requiring wide jaw opening will generally be heavier. However, there is a countering argument to be made that large objects are relatively rare, and most of the awkward loads will probably have grip features that can be engaged with the jaws nearly closed. Furthermore, the most critical payload is the retrieval end effector, which has a grip fixture. We decided to conduct a study of feasible variations to improve the gripper performance for this application.

To present the WREE to the working surfaces in the full range of required attitudes, it is necessary to grasp it from various directions. This problem had been solved earlier for the Oak Ridge Modified Light Duty Utility Arm (MLDUA) and the Confined Sluicing End Effector (CSEE) by means of a pair of X-handles (designed by SPAR Aerospace) mounted on a bracket placing their main axes at $90^{\circ}$ to each other. The X-handle had a large base cylinder and small X-bars, and the MLDUA gripper jaws engaged it with the wrist axis parallel to the base cylinder axis, allowing four gripper orientations (wrist roll positions) at each X-handle for a total of eight possible, of which one was impractical due to camera location on the gripper. 


\section{APPROACH}

\section{Conceptual}

Consider the original design illustrated in Figure 1. The jaws are driven by link epj. epj is driven by ae, generating a moment about p. For a constant force in $\boldsymbol{a e}$, the moment about $\mathbf{p}$ is maximum when $\boldsymbol{a} \boldsymbol{e}$ is normal to $\boldsymbol{e p}(\mathbf{a e p}=\pi / 2)$, and is zero when $\boldsymbol{a} \boldsymbol{e}$ and $\boldsymbol{e p}$ are parallel. For a constant jaw force the force in $\boldsymbol{a} \boldsymbol{e}$ due to the action of the piston rod is at a minimum, equal to the piston force (for a one-jaw study as illustrated), when $\boldsymbol{a} \boldsymbol{e}$ is in line with the axis of piston rod motion. The force in $\boldsymbol{a} \boldsymbol{e}$ can become very large as aep approaches normal. We sought a design that would keep a e nearly normal to $\boldsymbol{e p}$ and benefit to a degree from the force multiplication possible at oae.

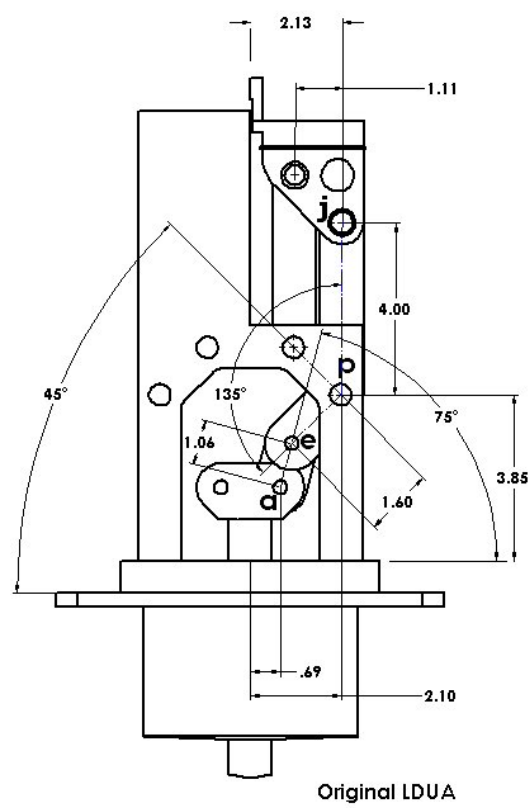

Figure 1: Simplified (one jaw) study geometry of the original LDUA gripper.

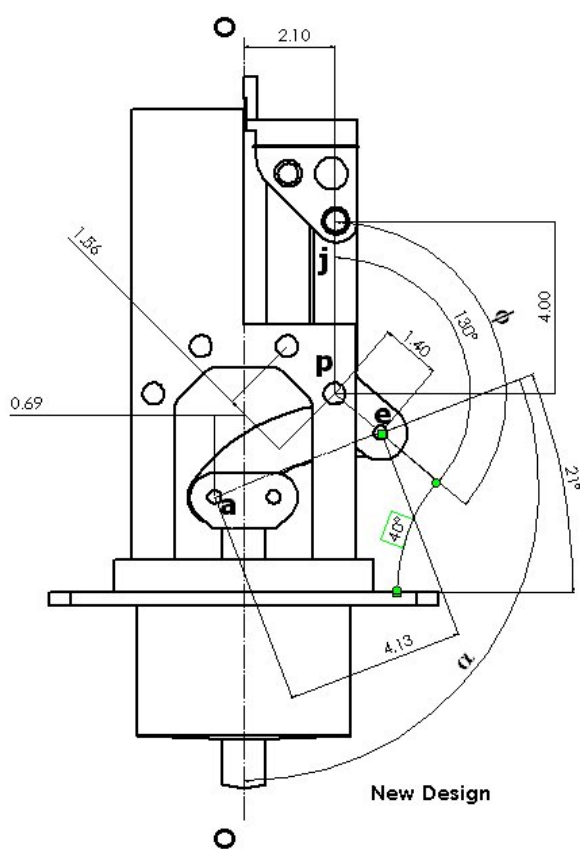

Figure 2: Redesigned gripper. Simplified (one jaw) study geometry.

The shortcomings of the base design were known from the outset. We recognized that a linkage where angle $\alpha$ is nearly $90^{\circ}$ (See Figure 2) at the closed jaw position would yield very high grip force and resist back-driving. The trade-off would be in the ratio of jaw travel to piston travel. Space constraints in the GEE base limit the piston travel to about $60 \mathrm{~mm}$.

\section{Calculations}

The analysis of the linkage is a straightforward 2-D kinematics problem. The base design and a new concept configuration were modeled in a simplified form and run through a kinematic analysis with DesignWorks ${ }^{\mathrm{TM}}$, an add-in package for SolidWorks ${ }^{\mathrm{TM}}$. It became apparent that fine-tuning could be accomplished much faster with a simple spreadsheet. We prepared a spreadsheet and validated the output against the 
DesignWorks ${ }^{\mathrm{TM}}$ results and baseline model test results, then used the spreadsheet to examine a number of other cases.

Several new linkage geometries were defined and analyzed until we determined that the crossed intermediate (ae) linkage shown in Figure 2 was the most promising. The actuator links ae were crossed and the doglegs in links epj were reversed, placing the joint $\mathbf{e}$ outboard of the pivot $\mathbf{p}$. The design was further refined by adjusting lengths $\underline{e p}$ and $\underline{a e}$ and angle $\phi$ to obtain the ranges of travel required.

Several more variations on that arrangement were analyzed, using an informal iterative procedure to increment the various parameters. Reversing the links epj but leaving the links $\boldsymbol{a} e$ un-crossed improved on the original design but not on the crossedlink arrangement. Better overall performance was obtained with an un-crossed intermediate link arrangement with e outboard, but the piston stroke required was excessive for the package.

No optimization routine was programmed for the analysis, and the criteria for selection of one result over another were informal as well - engineering evaluation of the force plots was cost effective and fast. _ FEA was performed to verify that linkage parts were strong enough to handle the loads imposed by the new configuration.

\section{Testing}

The jaw force was measured with a simple compression load cell and spacers inserted between the jaws to obtain grip force at a range of jaw displacements.

\section{RESULTS}

\section{Grip Fixture Design}

The GEE jaw and grip fixture was based on the SPAR Aerospace design used on the LDUA. For this application, we modified the X-handle and jaws so the jaws could engage the X-handle not only with the wrist and base parallel as before, but with the wrist axis normal to the base axis from any of four directions and in either of two wrist roll positions, thereby obtaining nine practical and three impractical grip orientations without requiring a second grip fixture and mounting bracket. The resulting grip fixture is longer and heavier than the prior X-handle design, but the net weight of one new fixture is less than that of two of the old fixtures with the required bracket. The practical grip orientations provide four distinct angles of approach between the end effector and the GEE axis, where the old design allowed only two.

While we planned to increase the grip force by refinements to the actuator linkage, we also took care in the evolution of the gripper jaws and end effector fixture to preserve the advantageous geometry of the X-handle, which reduces the grip force required to securely hold the WREE. The grip fixture and jaws were designed to react most of the forces transmitted from the end effector through the linkage to the base, rather than to the actuating piston. 


\section{Gripper Design}

We had a prototype of the original gripper on hand, so the preliminary design was built with the modified parts in aluminum and bench tested with a load cell between the jaws. The forces realized averaged $93 \%$ of the predicted forces, the losses accountable to friction in the cylinder and linkage.

The new grip fixture and jaw design (Figure 4) mated at a nominal jaw opening of about $11 \mathrm{~mm}$ (centerline axis to jaw face), so an actuator linkage that maximized force near that position would be preferred. Fairly constant grip force or a linear variation in force over the range of jaw motion was considered desirable for handling debris. The jaw could have been designed to grip the WREE at a position closer to fully closed, but this would present more pinch points and opportunities for debris or umbilical members to get trapped in the gripper.

The theoretical jaw force produced by the original design varied from 533N (120 lbf) at closed to $1600 \mathrm{~N}$ (360 lbf) at jaw displacement of $75 \mathrm{~mm}$ (3 inches) from centerline. The calculated forces for the new design at the same positions are $2300 \mathrm{~N}$ (510 lbf) and $1330 \mathrm{~N}(310 \mathrm{lbf})$. The range of piston travel is nearly the same for both cases. We obtained a force gain of $325 \%$ at the closed jaw position at a cost of $14 \%$ at the fully open position. (See Figure 3). The new design can subject the actuating piston rod to higher lateral forces, but if the payload rating of the EMMA is not exceeded the lateral forces on the piston rod should not be excessive.

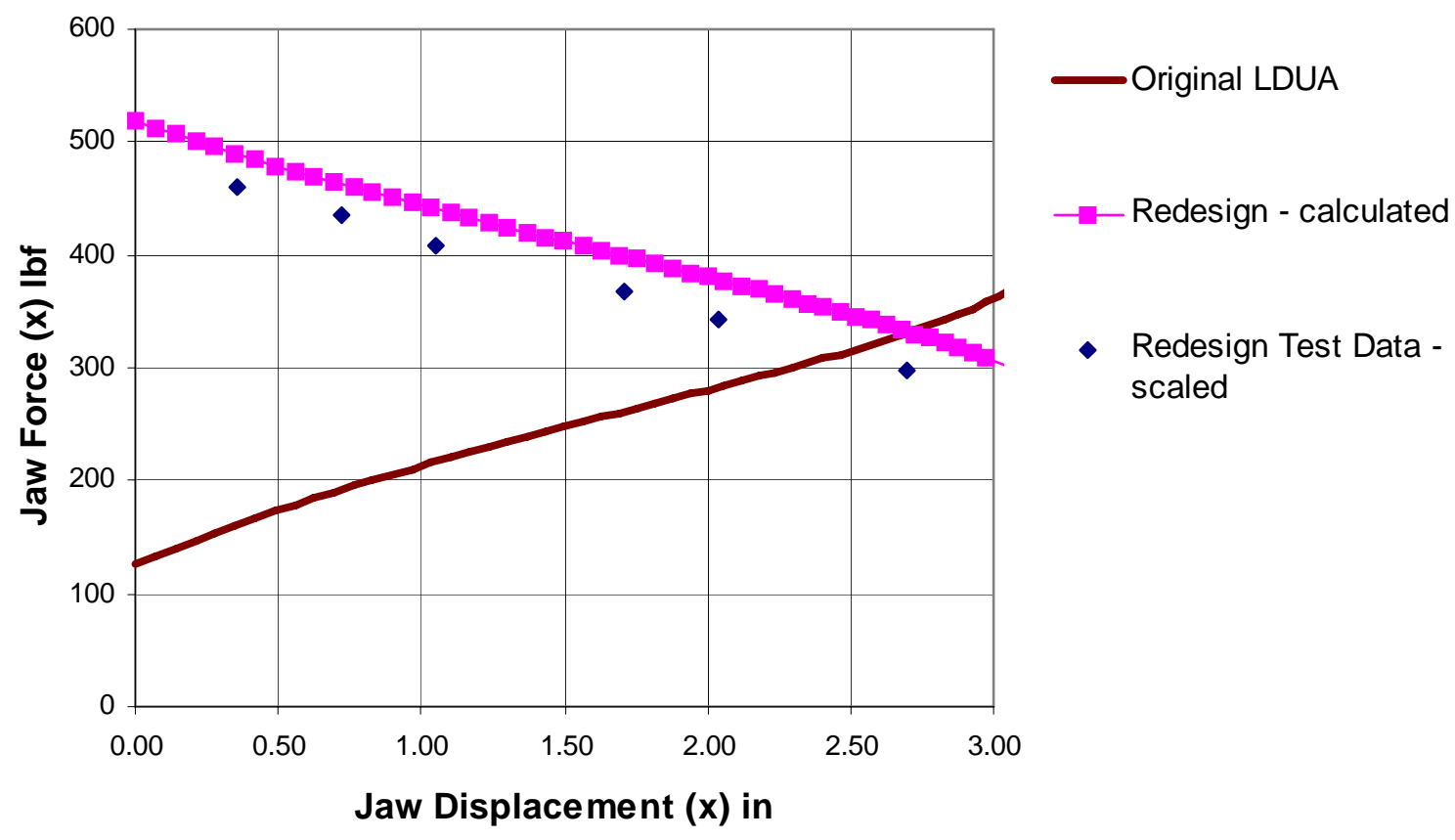

Figure 3: Comparison of calculated and test data. Testing data is scaled to the design working pressure from a lower test pressure (limited by shop air system). 


\section{Conclusion}

A reasonably brief and inexpensive analysis effort yielded a significant improvement in the performance of the gripping end effector and the mating grip fixture for the end effector and other payloads.

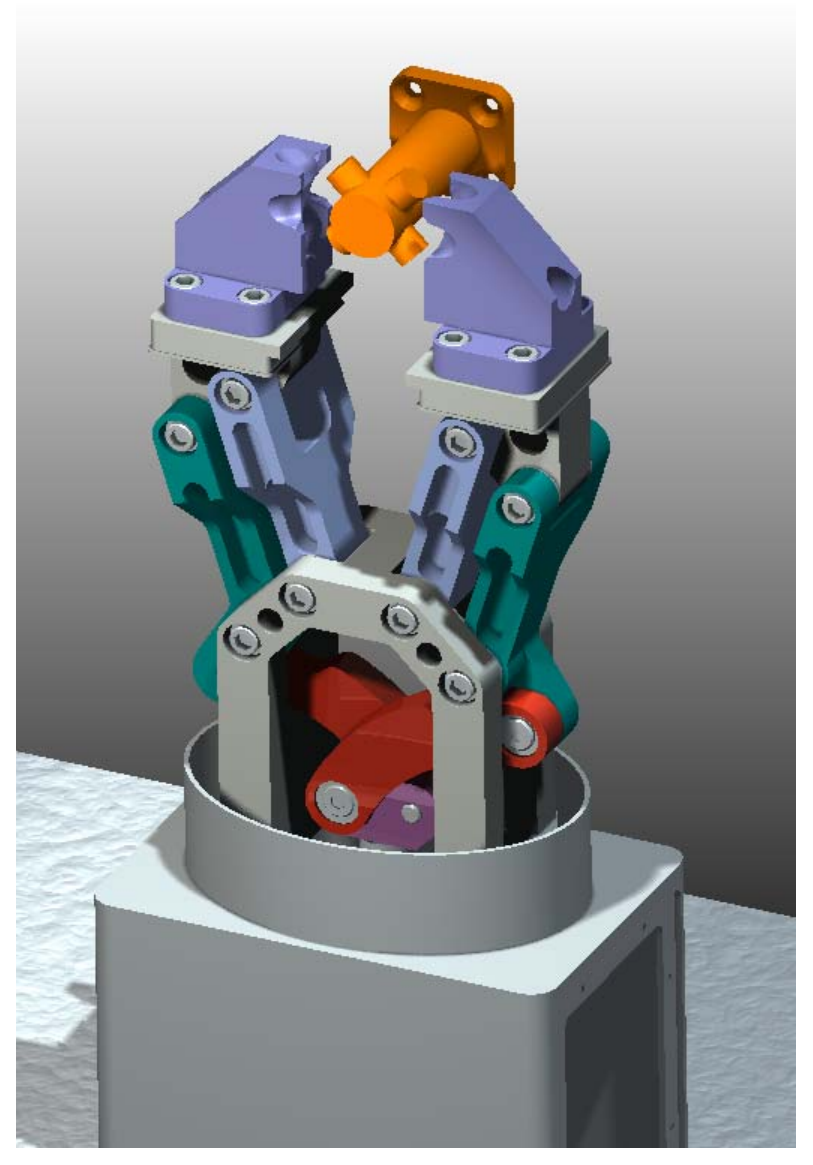

Figure 4: Rendering of the redesigned gripper end effector and the grip fixture. 